Brit. J. industr. Med., 1964, 21, 203.

\title{
USE OF SINGLE URINE SAMPLES FOR THE ASSESSMENT OF LEAD ABSORPTION
}

\author{
BY \\ M. K. B. MOLYNEUX \\ From the Nuffield Department of Occupational Health, University of Manchester
}

(RECEIVED FOR PUBLICATION JULY 22, 1963)

\begin{abstract}
The variation of urinary lead concentration ( $\mu \mathrm{g}$. $\mathrm{Pb} /$ litre) of short-period samples has been studied in a group of men exposed to inorganic lead dust. The urinary specific gravity was used to correct for the variation in urinary volume, but the residual variation was still too great to assess the mean lead concentration. The effect of creatinine correction was studied as an alternative, but there is no statistical difference between either method of correction. It is shown that the variation of lead concentration is related to the time of day. The highest concentration occurs at approximately $4.00 \mathrm{p} . \mathrm{m}$. in day workers.

The diurnal rhythm of the lead excretion rate $(\mu \mathrm{g} . \mathrm{Pb} /$ minute) is described in day and night shift workers. The rate of excretion rises to a maximum at approximately $5.00 \mathrm{p} . \mathrm{m}$. in the former but decreases in night workers, falling to a minimum at approximately $2.00 \mathrm{a} . \mathrm{m}$. The rhythm is independent of immediate exposure and is thought to be physiological in origin. The plasma lead clearance is estimated at $1.4 \mathrm{ml}$. plasma per minute. This suggests that only a small proportion of plasma lead may be ultrafiltrable and that little lead is secreted by the tubules.
\end{abstract}

The estimation of lead in the urine is used throughout industry, both for the group control of lead-exposed personnel and also for assessing the exposure of the individual. The variability existing in the uncorrected lead concentration of the single urine sample renders this technique open to much uncertainty, but its use continues, in preference to blood lead estimation, largely because of the relative ease of obtaining spot urine samples.

This investigation has been carried out to study in detail the variations encountered in the lead concentration and lead excretion rate in samples collected from subjects with widely different exposures. The results are assessed, taking into account the time of collection and correction by specific gravity and creatinine concentration.

\section{Lead and Specific Gravity}

The concentration of lead in a 24-hour urine sample has been associated with the mass of total urinary solids excreted over the same period of time. The mass of total urinary solids is related to the specific gravity of the urine, and the lead con- centration of a 24-hour urine sample can be related to the specific gravity by the formula:

$$
\text { Us }=\frac{\text { Uo } \times \text { Gs }}{\text { Go }}
$$

where Us is the standardized lead concentration ( $\mu \mathrm{g} . /$ litre), Uo is the observed lead concentration ( $\mu$ g./litre), Gs is the standard value of specific gravity, and Go is the observed value of specific gravity.

Provided that the rate of excretion of lead and that of the total urinary solids is related, this form of correction can be applied, with advantage, to the observed concentration of spot and short-period urine samples (Levine and Fahy, 1945). This work applies to several samples collected from a group of men, as does that of Pinto, Elkins, and Ege (1941), who applied correction by the formula:

$$
\mathrm{Us}=\mathrm{Uo} / \sqrt{\frac{\mathrm{V}}{\mathrm{T}}}
$$

where Us is the standardized lead concentration $(\mu \mathrm{g}$./litre), Uo is the observed lead concentration $(\mu \mathrm{g}$./litre), $\mathrm{V}$ is the volume of the sample, and $\mathrm{T}$ is 
the time over which the sample is collected (minutes). They obtained similar results. Both these methods are used to correct for variations in the volume of urine excreted.

The variation remaining in the lead concentration after correction by specific gravity indicates that some factor, other than a change in the urinary volume, is influencing the variation in concentration. This could be related to the diurnal rhythm of the lead excretion rate $(\mu \mathrm{g}$. $\mathrm{Pb} / \mathrm{min}$.) reported by Webster in 1941.

The choice of specific gravity for correction is open to serious criticism since it is dependent upon fluctuations in the output of sodium chloride.

\section{Correction by Creatinine}

Correction should ideally be made by reference to a urinary constituent that is excreted at a constant rate; changes in the concentration of this substance would be inversely related to the urinary flow rate.

Creatinine is a urinary constituent, the output of which varies only between narrow limits, and creatinine correction has been used by Smith and Kench (1957) for the correction of urinary cadmium concentration, but there is no evidence to suggest that lead and cadmium are excreted in the same way. Creatinine correction may be applied by the formula

$$
\mathrm{Us}=\frac{\mathrm{Uo} \times \mathrm{Cr}_{\mathbf{s}}}{\mathrm{Cr}_{\mathbf{o}}}
$$

where Us is the standardized lead concentration ( $\mu \mathrm{g}$./litre), Uo is the observed lead concentration ( $\mu \mathrm{g}$./litre), $\mathrm{Cr}_{\mathrm{g}}$ is the standard creatinine concentration, and $\mathrm{Cr}_{0}$ is the observed creatinine concentration.

\section{Techniques}

Statistical.-The two methods of standardization or of correction, based on the specific gravity and creatinine concentration, are compared, and the validity of the correction is determined by (a) a comparison of the coefficient of variation of lead concentration before and after correction, and $(b)$ the degree of association between lead concentration, specific gravity, and creatinine concentration.

Subjects.-These were employed in the manufacture of lead accumulators. The degree of exposure varied between individuals but all the subjects had had several years of exposure to inorganic lead dust.

Collection.-Spot samples were collected in borosilicate glass-stoppered bottles, previously de-leaded in the laboratory. The collection of samples during working hours was carried out under the supervision of the works medical department. A record was kept of the time of collection, the previous time of passing urine, and the total volume of the sample. The mean rate of excretion of lead and creatinine could thus be calculated.

Chemical.-The following techniques were used.

Lead in Urine.-Two methods of lead estimation were used.

In method 1, a dry ashing technique was used followed by dithizone extraction and a quantitative colorimetric lead determination (mixed colour method) using the Unicam S.P. 500 spectrophotometer. Interference from tin and bismuth was eliminated by dithizone extraction.

In method 2, a wet ashing technique was used followed by dithizone extraction and a colorimetric lead determination by the monocolour method (King and Thompson, 1961). Interference from bismuth was taken into account by a spectrophotometric technique.

The experimental error of both methods was within $\pm 5 \%$.

Creatinine in Urine.-The alkaline picrate method of Owen, Iggo, Scandrett, and Stewart (1954) was used.

Specific Gravity.-The same calibrated hydrometer was used throughout and all measurements were corrected to a temperature of $20^{\circ} \mathrm{C}$.

\section{Observations}

Variation of Lead Concentration after Correction.-

The degree of association between lead concentration and (a) specific gravity and $(b)$ creatinine concentration is shown in Table 1 . The association

\section{TABLE 1} DEGREE OF ASSOCIATION BETWEEN LEAD
CONCENTRATION AND (a) SPECIFIC GRAVITY AND (b) CREATININE CONCENTRATION

\begin{tabular}{|c|c|c|c|c|}
\hline \multirow{2}{*}{ Subject } & \multirow{2}{*}{$\begin{array}{l}\text { No. of } \\
\text { Samples }\end{array}$} & \multirow{2}{*}{$\begin{array}{c}\text { Mean } \\
\text { Lead } \\
\text { Conc. } \\
(\mu \mathrm{g} . / 1 .)\end{array}$} & \multicolumn{2}{|c|}{$\begin{array}{c}\text { Degree of Association } \\
\text { between Lead Conc. } \\
(\mu \mathrm{g} . / 1 .) \text { and }\end{array}$} \\
\hline & & & $\begin{array}{l}\text { Specific } \\
\text { Gravity }\end{array}$ & $\begin{array}{l}\text { Creatinine } \\
\text { Conc. }\end{array}$ \\
\hline $\begin{array}{l}\mathbf{B} \\
\mathbf{C} \\
\mathbf{D} \\
\mathbf{E} \\
\mathbf{J} \\
\mathbf{F} \\
\mathbf{G} \\
\mathbf{H} \\
\mathbf{I}\end{array}$ & $\begin{array}{l}14 \\
16 \\
13 \\
19 \\
20 \\
15 \\
17 \\
22 \\
21\end{array}$ & $\begin{array}{r}81 \\
88 \\
131 \\
187 \\
193 \\
208 \\
257 \\
266 \\
424\end{array}$ & $\begin{array}{r}+0.77 \\
+0.76 \\
+0.57 \\
+0.92 \\
+0.62 \\
+0.67 \\
+0.24 \\
+0.77 \\
+0.64\end{array}$ & $\begin{array}{r}+0.67 \\
+0.67 \\
+0.45 \\
+0.81 \\
+0.90 \\
+0.44 \\
+0.39 \\
+0.68 \\
+0.58\end{array}$ \\
\hline
\end{tabular}

varies widely between individuals and appears to be unrelated to the mean lead concentration. There is no difference in the association between lead and specific gravity and lead and creatinine concentration.

The variation in the lead concentration of single samples before and after correction is shown in Table 2. The coefficient of variation shows that correction by either method can reduce the variability in some subjects. The coefficient of variation 
USE OF SINGLE URINE SAMPLES FOR ASSESSMENT OF LEAD ABSORPTION 205

TABLE 2

MEAN AND COEFFICIENT OF VARIATION (V) OF OBSERVED, SPECIFIC GRAVITY CORRECTED AND CREATININE CORRECTED LEAD CONCENTRATION ( $\mu \mathrm{g}$.Pb/1.) OF SPOT SAMPLES

\begin{tabular}{|c|c|c|c|c|c|c|c|}
\hline \multirow{2}{*}{ Subject } & \multirow{2}{*}{$\begin{array}{c}\text { No. of } \\
\text { Observations }\end{array}$} & \multicolumn{2}{|c|}{ Observed } & \multicolumn{2}{|c|}{ S.G. Corrected } & \multicolumn{2}{|c|}{ Creatinine Corrected } \\
\hline & & Mean & V & Mean & $\mathbf{V}$ & Mean & $\mathbf{V}$ \\
\hline $\begin{array}{l}\mathbf{A} \\
\mathbf{B} \\
\mathbf{C} \\
\mathbf{D} \\
\mathbf{E} \\
\mathbf{F} \\
\mathbf{G} \\
\mathbf{H} \\
\mathbf{I}\end{array}$ & $\begin{array}{l}31 \\
14 \\
16 \\
13 \\
19 \\
15 \\
17 \\
22 \\
21\end{array}$ & $\begin{array}{r}72 \\
81 \\
88 \\
131 \\
187 \\
208 \\
257 \\
266 \\
424\end{array}$ & $\begin{array}{l}37 \cdot 4 \\
58 \cdot 4 \\
40 \cdot 3 \\
27 \cdot 9 \\
53 \cdot 1 \\
28 \cdot 6 \\
55 \cdot 8 \\
35 \cdot 2 \\
37 \cdot 8\end{array}$ & $\begin{array}{r}71 \\
106 \\
98 \\
174 \\
180 \\
219 \\
266 \\
276 \\
403\end{array}$ & $\begin{array}{l}32 \cdot 7 \\
63 \cdot 0 \\
37 \cdot 7 \\
69 \cdot 4 \\
32 \cdot 5 \\
33 \cdot 0 \\
43 \cdot 5 \\
27 \cdot 2 \\
30 \cdot 5\end{array}$ & $\begin{array}{r}73 \\
76 \\
89 \\
149 \\
197 \\
211 \\
256 \\
280 \\
389\end{array}$ & $\begin{array}{l}44 \cdot 3 \\
35 \cdot 2 \\
26 \cdot 2 \\
42 \cdot 1 \\
33 \cdot 9 \\
35 \cdot 2 \\
44 \cdot 5 \\
28 \cdot 6 \\
36 \cdot 7\end{array}$ \\
\hline
\end{tabular}

is unrelated to the mean lead concentration. The residual variation after correction is large in some subjects.

The standard values of specific gravity and creatinine concentration used for this comparison are the mean values for each subject. This is considered most suitable since the range of individual mean specific gravity was 1,008 to 1,021 compared with a group mean of 1,015 . The range of individual mean creatinine concentration was 385 to $840 \mu \mathrm{g} . / \mathrm{ml}$. compared with a group mean of $577 \mu \mathrm{g} . / \mathrm{ml}$. The use of a group value of standard specific gravity or of creatinine concentration would result in a greater variation between the observed and corrected mean lead concentration.
TABLE 3

MEAN OBSERVED LEAD CONCENTRATION ( $\mu \mathrm{g} . \mathrm{Pb} / 1$.$) IN$ RELATION TO TIME OF DAY (8 SUBJECTS)

\begin{tabular}{c|c|c|c|c|c}
\hline Time & $6-7$ a.m. & $8-10$ a.m. & $11-1$ p.m. & $2-3$ p.m. & $4-5$ p.m. \\
\cline { 2 - 4 } $\begin{array}{c}\text { Mean } \\
\text { conc. }\end{array}$ & 138 & 190 & 212 & 237 & 368 \\
\hline Range & $74-282$ & $45-325$ & $70-369$ & $107-492$ & $275-592$ \\
\hline
\end{tabular}

Diurnal Variation in Lead Concentration.-Table 3 shows the mean lead concentration (uncorrected) of samples from eight lead-exposed subjects, collected at approximately the same time on each of five working days (6.00 a.m. to 5.00 p.m.).

TABLE 4

VARIATION IN LEAD CONCENTRATION: ESTIMATES OF VARIANCE SHOWING THE EFFECT OF ELIMINATION OF VARIATION DUE TO TIME OF COLLECTION

\begin{tabular}{|c|c|c|c|c|c|}
\hline \multirow{2}{*}{ Man } & \multirow{2}{*}{ Source of Variation } & \multirow{2}{*}{ d.f. } & \multirow{2}{*}{ Observed } & \multicolumn{2}{|c|}{ Estimates of Variance } \\
\hline & & & & S.G. Corrected & $\begin{array}{l}\text { Creatinine } \\
\text { Corrected }\end{array}$ \\
\hline $\mathbf{A}$ & $\begin{array}{l}\text { Diurnal rhythm } \\
\text { Residual }\end{array}$ & $\begin{array}{r}7 \\
23\end{array}$ & $\begin{array}{l}743 \\
715\end{array}$ & $\begin{array}{l}694 \\
492\end{array}$ & $\begin{array}{l}1005 \\
1054\end{array}$ \\
\hline B & $\begin{array}{l}\text { Diurnal rhythm } \\
\text { Residual }\end{array}$ & $\begin{array}{l}4 \\
9\end{array}$ & $\begin{array}{l}2384 \\
2162\end{array}$ & $\begin{array}{l}5513 \\
3982\end{array}$ & $\begin{array}{l}751 \\
669\end{array}$ \\
\hline $\bar{C}$ & $\begin{array}{l}\text { Diurnal rhythm } \\
\text { Residual }\end{array}$ & $\begin{array}{r}4 \\
11\end{array}$ & $\begin{array}{r}2305 \\
870\end{array}$ & $\underset{624}{3375+}$ & $\begin{array}{l}657 \\
499\end{array}$ \\
\hline D & $\begin{array}{c}\text { Diurnal rhythm } \\
\text { Residual }\end{array}$ & $\begin{array}{l}3 \\
9\end{array}$ & $\begin{array}{l}2872 \\
2038\end{array}$ & $\underset{1744}{52970+++}$ & $\begin{array}{l}4900 \\
3586\end{array}$ \\
\hline $\mathbf{E}$ & $\begin{array}{l}\text { Diurnal rhythm } \\
\text { Residual }\end{array}$ & $\begin{array}{r}3 \\
15\end{array}$ & $\underset{3959}{39386}+++$ & ${ }_{2332}^{8892+}$ & $\begin{array}{l}9015 \\
3533\end{array}$ \\
\hline F & $\begin{array}{c}\text { Diurnal rhythm } \\
\text { Residual }\end{array}$ & 13 & $\begin{array}{l}8961+ \\
2066\end{array}$ & $24541++$ & $\begin{array}{l}9703 \\
4375\end{array}$ \\
\hline $\mathbf{G}$ & $\begin{array}{l}\text { Diurnal rhythm } \\
\text { Residual }\end{array}$ & $\begin{array}{r}3 \\
13\end{array}$ & $\begin{array}{l}49310 \\
21516\end{array}$ & $\begin{array}{l}10351 \\
14018\end{array}$ & $\begin{array}{r}32709 \\
8394\end{array}$ \\
\hline $\mathbf{H}$ & $\begin{array}{l}\text { Diurnal rhythm } \\
\text { Residual }\end{array}$ & $\begin{array}{r}4 \\
17\end{array}$ & $\underset{5807}{22608+}$ & $\begin{array}{l}1770 \\
6534\end{array}$ & $\begin{array}{r}10460 \\
5436\end{array}$ \\
\hline I & $\begin{array}{l}\text { Diurnal rhythm } \\
\text { Residual }\end{array}$ & $\begin{array}{r}4 \\
16\end{array}$ & $\begin{array}{l}86254 \\
10424\end{array}$ & $\begin{array}{l}43096++ \\
8097\end{array}$ & $\underset{9433}{63964}++$ \\
\hline
\end{tabular}

$+0.05>P>0.01$

$++0.01>P>0.001$

$+++\mathbf{P}<0.001$ 
There is a tendency in each of these individuals for the samples of the highest lead concentration to occur in the latter part of the working day. A similar observation was made by Kehoe (1947). The specific gravity and creatinine concentration also tend to reach their maximum at this time.

In Table 4 the analysis of variance shows that the diurnal variation of lead concentration observed in each individual is a contributing factor to the total variation. This diurnal variation is observed before and after correction and is a result of both changes in the urinary flow rate and changes in the rate of lead excretion. The diurnal rhythm of the lead excretion rate has been studied in workmen during exposure and periods of non-exposure and also during the day and night shifts.

Diurnal Rhythm of Lead Excretion Rate.Excretion Rate during Exposure Period: (a) Day Workers (6.00 a.m. to 4.00 p.m.)-Observations on the rate of lead excretion $(\mathrm{m} \mu \mathrm{g}$. $\mathrm{Pb} / \mathrm{min}$.) during the working day from $6.00 \mathrm{a} . \mathrm{m}$. to $4.00 \mathrm{p} . \mathrm{m}$. agree with those of Webster (1941). Figure 1 illustrates the change in rate observed in a group of six men during the working day. Each point represents the mean lead excretion rate on five working days.
The time indicated represents the mid-point of each period during which the samples were collected.

The mean rate of lead excretion is minimal during sleep and rises to a maximum later in the day. All these workmen were exposed to lead dust from 7.00 a.m. to 4.30 p.m.

(b) Shift Workers (10.00 p.m. to 6.00 a.m.).-The diurnal rhythm observed in a group of five nightshift workers is also illustrated in Figure 1. Samples were collected between the hours of 10.00 p.m. and 6.00 a.m. during the period of exposure. The lead excretion rate is minimal during the period 12 midnight to 3.00 a.m. This is consistent with the earlier observation that in day workers the mean lead excretion rate is lowest between 11.00 p.m. and 6.00 a.m. The change in lead output appears to be unrelated to the immediate period of exposure.

(c) Shift Workers (11.00 a.m. to 10.00 p.m.).-In two workmen on the afternoon shift the lead excretion rate fell during the exposure period, reaching a minimum at approximately 6.00 p.m.

Excretion Rate during Non-exposure Period.These observations were repeated with three workmen during a period of non-exposure. This was during a two-day rest between the end of one shift and the beginning of another.
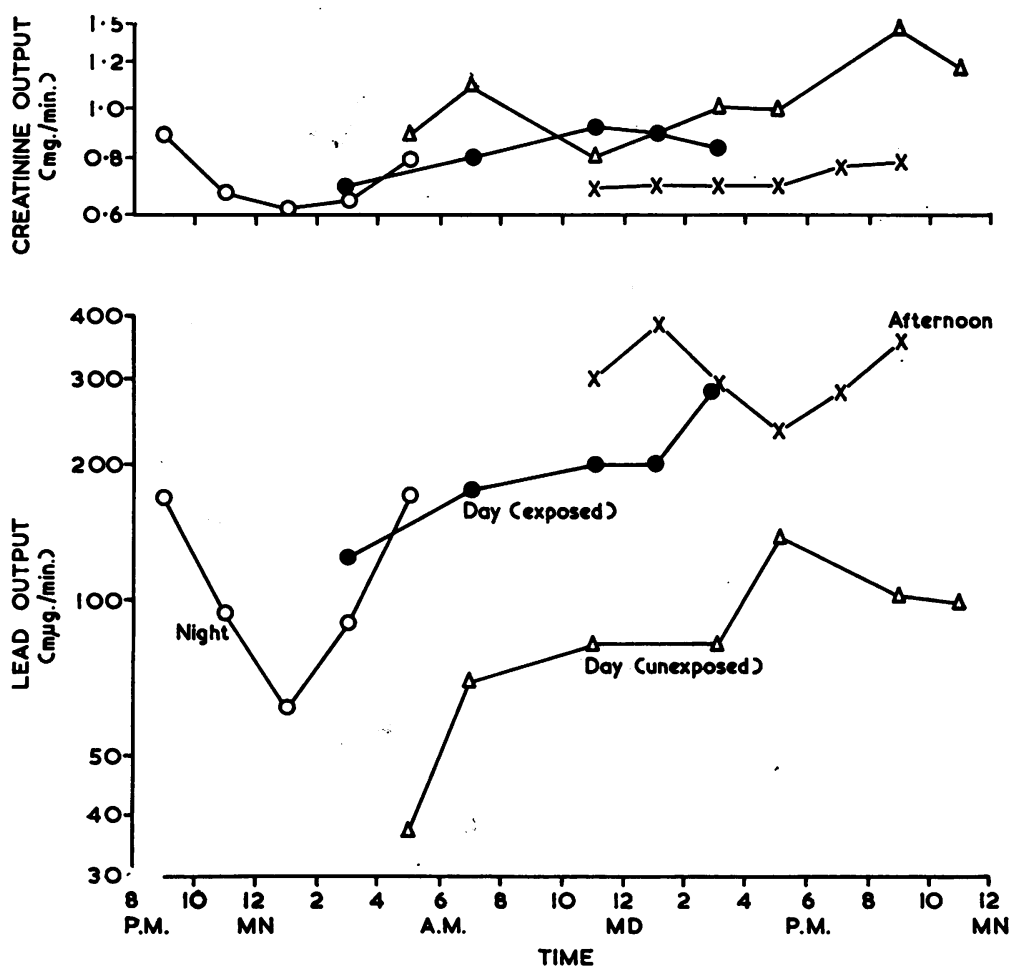

Fig. 1.-Diurnal rhythm of urinary lead and creatinine. 
All subjects have the lowest lead output between the hours of midnight and $6.00 \mathrm{a} . \mathrm{m}$. The time of maximum excretion rate occurs at about 6.00 p.m.

The results reported here refer entirely to the total lead excreted in the urine. Preliminary observations indicate that the precipitable component of the total lead has the same rhythm.

Emphasis has been placed on observations made on men employed in an inorganic lead works. The grouped results adequately represent the rhythm of the individuals concerned, but the recognition of a diurnal rhythm under these circumstances may be criticized. Errors involved in the estimation of mean lead excretion arise from (1) incomplete emptying of the bladder, (2) failure to record the correct sampling time, and (3) failure to collect the total volume voided.

Errors due to (2) and (3) are thought to have been successfully overcome by the co-operation of the workmen. Errors due to (1) are difficult to assess, particularly in 'untrained' subjects. It is thought, however, that none of these factors has substantially influenced the over-all impression of the diurnal rhythm.

\section{Discussion}

Diurnal Variation of Corrected Lead Concentration.-It has been shown that the diurnal variation of lead excretion influenced both the corrected and observed results. A comparison of the variation in the lead and creatinine excretion rate enables us to explain the limitation of correction by creatinine.

Figure $2 \mathrm{a}$ shows the creatinine-corrected and observed lead concentrations of samples collected from a subject with a mean lead concentration of $96 \mu \mathrm{g}$. $\mathrm{Pb} / \mathrm{l}$. The samples collected at work from 8.00 a.m. to 4.00 p.m. follow the same pattern in both cases. The relatively constant creatinine output from 8.00 a.m. onwards is accompanied by a steadily increasing lead output (Fig. 2b). Consequently, the corrected lead concentration will increase much the same as the observed concentration and will be high relative to the individual mean concentration.

The reverse effect can be expected when the lead concentration is corrected in the night-shift worker between the hours of 2.00 a.m. and 4.00 a.m. (Fig. 1). Because of the high association between specific gravity and creatinine concentration, the same effect can be expected when correction is applied by the former.

Interpretation of Urinary Lead Concentration.Figure 3 shows the variation of lead concentration in two subjects. The observed, specific gravitycorrected, and creatinine-corrected lead concentra-
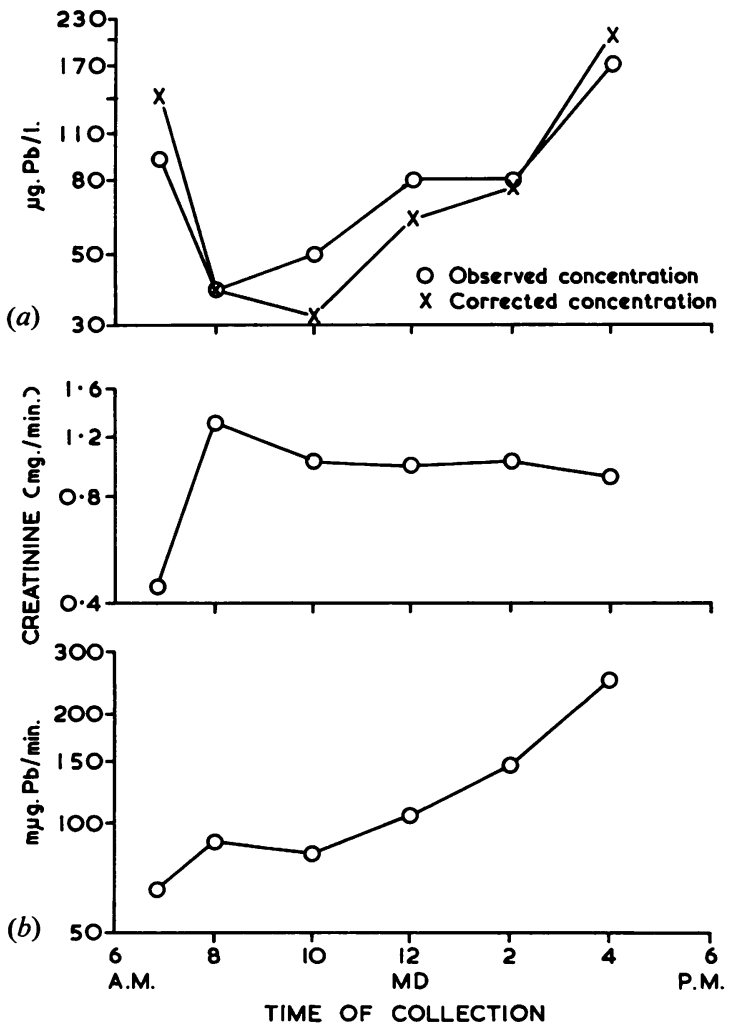

FIG. 2.-Comparison of lead concentration and excretion rate. (a) Variation of observed and corrected concentrations. (b) Variation of lead and creatinine excretion rates.

tions are compared when samples were collected at specified times of the day.

Many of the samples collected early in the morning are below the individual mean concentration.

Samples collected at noon are within a range which is more comparable with the mean concentration.

The lead concentration of spot samples collected at $4.00 \mathrm{p} . \mathrm{m}$. is relatively high compared with the individual mean concentration.

Samples collected between 3.00 p.m. and 4.00 p.m. are most reliable for identifying men with excessive levels of lead excretion. At this time few samples of abnormally low concentration occur.

By using the individual mean value of specific gravity and creatinine concentration, the variation in lead concentration may be reduced in some men. There is no statistical evidence to favour the exclusive use of either of these two methods.

The results indicate that the diurnal rhythm of the lead excretion rate has a major influence on the variation in concentration, particularly in subjects 


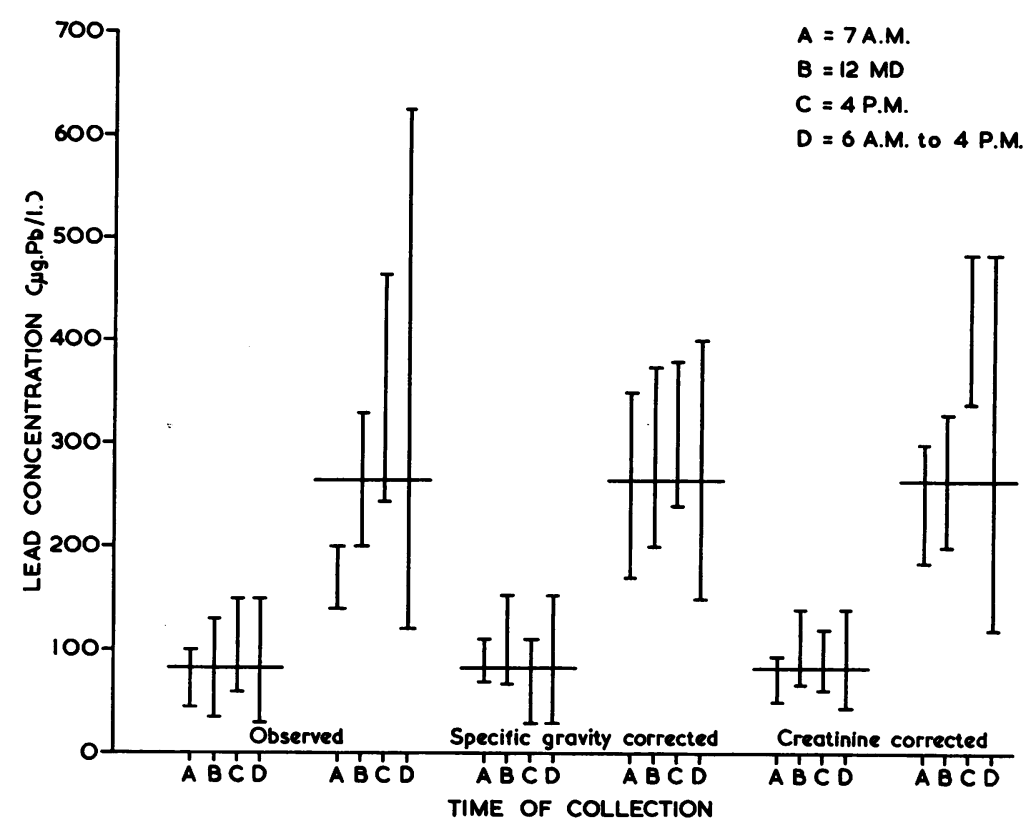

Fig. 3.-Effect of time of collection on the observed and corrected lead concentrations.

with a mean lead concentration in excess of $200 \mu \mathrm{g}$. $\mathrm{Pb} / \mathrm{l}$. The collection of a single sample, as in this group of men, at a standard time is therefore considered essential.

For any one man, when the time of collection and either method of correction is applied, the concentration of any one spot sample may still be an unreliable indication of the mean lead concentration. When the results are being compared with a 'maximum allowable concentration of lead in the urine', collection late in the working day should increase the reliability.

It should be noted that the correction of samples of a specific gravity of less than 1,010 was responsible for a considerable increase of variation after correction. This was less marked when creatinine concentration was used for the correction.

Diurnal Rhythm of Lead Excretion Rate.-The present study has confirmed and enlarged upon the original observations of Webster (1941). The diurnal rhythm of lead excretion in exposed day workers produces a maximal excretion rate between 3.00 p.m. and 6.00 p.m. and a minimal excretion rate during sleep, between midnight and 6.00 a.m. Since the rhythm exists under conditions of normal working exposure, it could be argued that the increased absorption of lead dust was responsible for the increased output.
This rhythm has, however, been shown in workmen during their non-exposure period. In these men recently absorbed lead is unlikely to have had any effect on the rhythm, and the slow absorption of ingested lead, although likely to influence the mean 24-hour lead output (Kehoe, 1960), is unlikely to have any influence on the relatively rapid increase observed in the afternoon.

In night-shift workers the minimum period of excretion is observed between $2.00 \mathrm{a} . \mathrm{m}$. and $4.00 \mathrm{a} . \mathrm{m}$. If inspired lead had any direct influence on the rhythm, the excretion rate would be expected to rise rather than fall at this time. It can be concluded that the rhythm is independent of immediate exposure and a rise in blood lead concentration.

The data presented in this paper do not permit a differentiation of the kind of mechanism, but the following points may be considered.

Preliminary observations on one lead worker show that the clearance of plasma lead is of the order of $1.4 \mathrm{ml}$. plasma per minute. This can be compared with the value quoted by Pinto et al. (1941) of $0.29 \mathrm{ml}$. blood per minute. The latter, referring to total blood, is probably not valid in view of the finding that 90 to $95 \%$ of blood lead is found on the erythrocytes (Clarkson and Kench, 1958). The diurnal rhythm could result from variations in tubular reabsorption or secretion and from variations in the glomerular filtration rate and 
in the concentration of ultrafiltrable lead in plasma.

The low plasma clearance shows that plasma lead is either not freely filtrable at the glomerulus or that it is largely removed from the ultrafiltrate by the tubules. The secretion of lead by the tubules themselves cannot be excluded but it cannot be very great.

My thanks are expressed to Professor R. E. Lane and those members of his department, Miss I. Dingwall Fordyce, Dr. D. Turner, and Dr. D. Malcolm, who assisted with the presentation of this paper and with the collection of samples.

\section{REFERENCES}

Clarkson, T. W., and Kench, J. E. (1958). Biochem. J., 69, 432. Kehoe, R. A. (1947). Occup. Med., 3, 156. - (1960). The Harben Lectures.

King, E., and Thompson, A. R. (1961). Ann. occup. Hyg., 3, 247. Levine, L., and Fahy, J. P. (1945). J. industr. Hyg., 27, 217.

Owen, J. A., Iggo, B., Scandrett, F., and Stewart, C. P. (1954). Biochem J. 58, 426.

Pinto, S. S., Elkins, H. B., and Ege, J. F. (1941). J. industr. Hyg., 23.

Smith, J. C., and Kench, J. E. (1957). Brit. J. industr. Med., 14, 240.

Webster, S. H. (1941). Publ. Hlth Rep. (Wash.), 56, 1834. 